\title{
Use of Compressive Osseointegration Endoprostheses for Massive Bone Loss From Tumor and Failed Arthroplasty: A Viable Option in the Upper Extremity
}

\author{
Krista A. Goulding MD, MPH, Adam Schwartz MD, Steven J. Hattrup MD, \\ R. Lor Randall MD, Donald Lee MD, Damian M. Rispoli MD, \\ Daniel M. Lerman MD, Christopher Beauchamp MD
}

Received: 19 September 2016/ Accepted: 18 January 2017/Published online: 13 February 2017

(C) The Association of Bone and Joint Surgeons (B) 2017

\begin{abstract}
Background Endoprostheses using principles of compressive osseointegration have shown good survivorship in several studies involving the lower extremity; however, no series to our knowledge have documented the use of this technology in the management of massive bone loss in the upper limb.
\end{abstract}

One of the authors certifies that he (SJH) has received payments, during the study period, an amount of less than USD 10,000 from Zimmer (Warsaw, IN, USA).

One of the authors certifies that he (RLR) has received payments, during the study period, an amount of USD 10,000-100,000 from Zimmer Biomet (Warsaw, IN, USA).

One of the authors certifies that he (DL) has received royalties during the study period of less than USD 10,000 from Biomet (Warsaw, IN, USA) and of less than USD 10,000 from Elsevier (New York, NY, USA).

All ICMJE Conflict of Interest Forms for authors and Clinical Orthopaedics and Related Research ${ }^{\mathbb{R}}$ editors and board members are on file with the publication and can be viewed on request.

Clinical Orthopaedics and Related Research ${ }^{\mathbb{R}}$ neither advocates nor endorses the use of any treatment, drug, or device. Readers are encouraged to always seek additional information, including FDAapproval status, of any drug or device prior to clinical use.

Each author certifies that his or her institution approved the human protocol for this investigation, that all investigations were conducted in conformity with ethical principles of research, and that informed consent for participation in the study was obtained.

This study was performed at The Mayo Clinic, Phoenix, AZ, USA.

K. A. Goulding ( $\square)$

McGill University Health Centre, 1650 Avenue Cedar, Montreal,

QC H3G 1A4, Canada

e-mail: krista.goulding@mcgill.ca

A. Schwartz, S. J. Hattrup, C. Beauchamp

The Mayo Clinic, Mayo Clinic Hospital, Phoenix, AZ, USA
Questions/purposes (1) What proportion of upper extremity implants using compressive osseointegration fixation principles achieved durable short-term fixation, and what were the modes of failure? (2) What surgical complications resulted from reconstruction using this technique?

Methods A multiinstitutional retrospective review identified nine patients (five women; four men) who underwent 13 endoprosthetic replacements between 2003 and 2014 using compressive osseointegration (Compliant ${ }^{\circledR}$ Prestress Device [CPS]; Biomet Inc, Warsaw, IN, USA) in the upper extremity, including two proximal humeri, two humeral diaphyses, seven distal humeri, and two proximal ulna. During the early part of that period, the indication for use of a compressive prosthesis in our centers was revision of a previous tumor reconstruction (allograft-prosthetic composite or stemmed endoprosthetic reconstruction) (three patients; five implants), or revision arthroplasty with massive bone loss (three patients, four implants); more recently, indications became somewhat more permissive and included posttraumatic bone loss (one patient, one implant), primary bone sarcoma, and resections with very short remaining end segments after diaphyseal resections (two patients, three implants). Minimum followup was 24 months; one patient (one implant) was lost to followup before that time with the implant intact at 14 months and no patients have died. The mean age of the patients was 45

\author{
A. Schwartz \\ e-mail: schwartz.adam@mayo.edu \\ R. L. Randall \\ Huntsman Cancer Institute, Salt Lake City, UT, USA
}


years (range, 21-62 years). Mean followup was 68 months (range, 24-141 months). Implant revision for any cause and for failure of the CPS mechanism was recorded. Modes of failure were categorized as soft tissue, aseptic loosening, structural, infection, and tumor progression; CPS modes of failure were defined as lack of fixation, with or without bone or implant fracture.

Results Of the 12 implants accounted for beyond 2 years, six had undergone revision of any kind. Only two revisions in two patients were attributable to lack of CPS fixation at the bone-implant interface; one of the patients also had periprosthetic and implant fracture develop through the traction bar. Other modes of failure were aseptic loosening of the standard ulnar component (two patients, two implants), bushing wear (one patient; one implant) and infection resulting in two-stage exchange and free soft tissue transfer with retention of the CPS spindle (one patient, one implant). Complications for all nine patients included one transient radial nerve palsy, one ulnar nerve sensory neurapraxia, one superficial infection, and two glenohumeral subluxations, one underwent revision surgery with implantation of a constrained liner.

Conclusions A compressive osseointegration endoprosthesis is an option for very difficult revisions or sarcoma resection in the upper extremity in which the remaining segment of host bone is too short for a conventional prosthesis. However, surgeons must inform patients that these are salvage operations, and revision surgery is common. Long-term followup of more patients is necessary to further document the survivorship of these implants in the upper extremity.

Level of Evidence Level IV, therapeutic study.

\section{Introduction}

Massive bone loss in the upper extremity is a challenging problem, in terms of the technical demands of reconstructing these defects and in improving patient function. In the upper extremity, endoprosthetic replacement represents one of a host of treatment modalities, including osteoarticular allografts, irradiation with reimplantation, claviculo pro humeri [7], and allograft-prosthesis composite

D. Lee

Vanderbilt Orthopaedic Institute Medical Center East, Nashville, TN, USA

D. M. Rispoli

Holy Spirit Hospital, A Gesinger Affiliate Associate, Danville, PA, USA

D. M. Lerman

University of Maryland Greenebaum Cancer Center, Baltimore, MD, USA reconstruction (Table 1). Endoprosthetic replacement is most commonly used for reconstruction after bone sarcoma resection; however, failed shoulder and elbow arthroplasty and massive posttraumatic bone loss are also potential indications for this procedure [10, 31].

The proximal humerus is a common location for primary and secondary malignancies involving bone $[8,9]$. Tumors involving the elbow are less common $[18,27]$ and make up less than $1 \%$ of all bone sarcomas [18]. Aseptic loosening along with infection and instability are the most commonly reported complications in these patient populations $[2,8,9,11,14,18,20,22,24-28,30,32]$.

Endoprostheses using principles of compressive osseointegration have been used with success in the lower extremity with similar rates of survivorship as more-traditional stemmed implants $[6,16,21,23]$. The technology involves compression of a porous-coated spindle at the bone-implant interface by applying a preselected amount of force through spring-loaded Belleville washers and a traction bar, which is secured in adjacent bone with pin fixation. Its design is intended to enhance osseointegration through stable compression, preventing stress shielding and thus reducing the prevalence of aseptic loosening [21]. The implant is particularly useful in large bony defects with a small remaining end segment, where replacement of the entire length of the bone might otherwise be required [6]. We are aware of only two other published case reports, both from our institutions, discussing the use of the Compress ${ }^{\circledR}$ Compliant Pre-stress Device (CPS) (Biomet Inc, Warsaw, IN, USA) [10, 15] in the upper extremity. The current study extends the followup for these four patients and includes additional patients and surgical locations in a multicentered approach from institutions with expertise in this unique form of reconstruction.

We therefore asked (1) What proportion of upper extremity implants using compressive osseointegration fixation principles achieved durable short-term fixation, and what were the modes of failure? (2) What surgical complications resulted from reconstruction using this technique?

Table 1. Options for reconstruction of massive bone loss in the upper extremity
Compressive osseointegration endoprosthesis
Cemented or uncemented stemmed endoprosthesis
Allograft prosthetic composite
Allograft + / - vascularized fibula
Osteoarticular allograft
Claviculo pro humeri
Irradiation with reimplantation 


\section{Patients and Methods}

A multiinstitutional retrospective study involving four institutions from 2003 to 2014 identified nine patients (five women; four men) who were treated with 13 upper extremity endoprosthetic replacements using the CPS. Inclusion criteria for the study were skeletally mature adults older than 18 years treated with a CPS implant for reasons of malignancy, arthroplasty, or trauma involving the upper extremity.

Patient demographics, details of prior surgery, and indication for the CPS were recorded (Table 2). CPS implant variables such as the anchor plug size, number of fixation pins, amount of force applied, implant revision for any cause, revision for failure of the CPS mechanism, and the timing of implant revision were tabulated for all patients with a minimum 24-month followup (Table 3). Modes of failure were categorized as soft tissue, aseptic loosening, structural, infection, and tumor progression, per Henderson et al. [17]; CPS modes of failure were defined as lack of fixation, with or without bone or implant fracture [16]. All surgical complications were recorded for the entire cohort of nine patients (Table 4). Four patients were previously reported on in case reports from our institutions [10, 15], but are included to extend the followup for these implants and to add additional patients from other centers known to be performing this type of reconstruction.

Mean followup was 68 months (range, 24-141 months) for the eight patients with a minimum followup of 24 months; one patient (one implant) was lost to followup before that time with the implant intact at 14 months. For all nine study patients, the mean age was 45 years (range, 21-62 years). Five of nine patients had an initial diagnosis of a primary malignant bone tumor (two osteosarcoma, one Ewing's sarcoma, one spindle cell sarcoma, one malignant bone tumor not otherwise specified). These patients were treated with chemotherapy and surgery; none received radiation. Three patients had loose, infected total elbow arthroplasties, and one patient had massive bone loss in the setting of an open fracture. The distal humerus was involved in six patients, the proximal humerus in two, and the humeral diaphysis in one. All infections were managed with two-stage revision with removal of all previous implants, insertion of an antibiotic-impregnated spacer, and intravenous antibiotics before insertion of the CPS implant.

Surgical Indications and Technique

During the early part of the study period, the indications for use of a compressive prosthesis in our centers was revision of a previous tumor reconstruction (allograft-prosthetic composite or stemmed endoprosthetic reconstruction) (three patients; five implants), or revision arthroplasty with massive bone loss (three patients, four implants); more recently, indications became somewhat more permissive and included posttraumatic bone loss (one patient, one implant), primary bone sarcoma (one patient; one implant), and resections with very short remaining end segments after diaphyseal resection (one patient; two implants). Seven patients overall had the CPS implanted in the setting of very difficult revision surgery; two patients with sarcoma had multiple revisions of allograft prosthetic composites, one patient with trauma with an open fracture and $12 \mathrm{~cm}$ of bone loss had previous cement spacers and external fixation, and four patients had bone deficiency and loss of fixation in the setting of total elbow arthroplasty or endoprosthetic replacement (three infections; one aseptic loosening). The CPS was implanted primarily in one patient with a diaphyseal tumor and one with a proximal humeral primary bone sarcoma.

The Mini Compress ${ }^{\circledR}$ Compliant Pre-stress Device (Biomet Inc) was used in all patients at the bone-implant interface [8]. This was coupled with various modular endoprostheses to replace the segmental humeral bone loss. In distal humeral replacements, this was coupled with a fully constrained, hinged, cemented standard ulnar component. A custom Compress ${ }^{\circledR}$ implant was designed for use in the proximal ulna in one patient.

Preoperatively, the cortical thickness was measured, ensuring there was a minimum $2.5 \mathrm{~mm}$. Requirements for remaining juxtaarticular bone was $4.6 \mathrm{~cm}$ to insert the short anchor plug and traction bar. After marking orientation, the bone was osteotomized perpendicular to its long axis. The bone then either was removed en bloc with the tumor or the previous arthroplasty bony cuts were refreshed to the appropriate level. A standard or short anchor plug then was selected, and the triple reamer was used to prepare the intramedullary canal [5]. The final triple reamer determined the anchor plug and centering sleeve sizes. An extramedullary drill guide was attached to the final anchor plug, which was inserted in the bone. This device was used to guide the transverse fixation pins, which are tapped into place after drilling of the bone. The number of transverse fixation pins depended on the cortical thickness and on the anchor plug size (Table 3). A face reamer then was used to prepare the osteotomized bone for the spindle. A centering sleeve helped to align the spindle with the traction bar and anchor. The amount of compressive force then was selected; 400 pounds was used for the majority of patients. No defined method of force selection currently exists, however, the maximum force tolerable to the remaining bone stock is the goal, and tends to be $800 \mathrm{~N}$ in the lower extremity and $400 \mathrm{~N}$ in the upper extremity. The nut driver was tightened, thereby compressing the Belleville washers, 
Table 2. Patient demographics, previous surgery, and indications for a compressive osseointegration endoprosthesis

\begin{tabular}{|c|c|c|c|c|c|c|}
\hline Patient & Age (years) & Gender & Diagnosis & Site & Previous surgery & Indication for CPS \\
\hline 1 & 45 & Female & Fibroblastic osteosarcoma & DH & $\begin{array}{l}\text { Inadvertent curettage + ORIF; } \\
\text { wide resection + APC }\end{array}$ & $\begin{array}{l}\text { Nonunion and } \\
\text { aseptic loosening }\end{array}$ \\
\hline 2 & 62 & Male & Osteosarcoma & DH & $\begin{array}{l}\text { Extraarticular resection + multiple } \\
\text { revisions APC (3); fascia lata } \\
\text { and Achilles allograft for triceps } \\
\text { insufficiency }\end{array}$ & Aseptic loosening \\
\hline 3 & 21 & Female & Open fracture & DH & $\begin{array}{l}\text { Irrigation, débridement, and } \\
\text { external fixation }\end{array}$ & $\begin{array}{l}\text { Open fracture with } \\
\text { massive bone loss }\end{array}$ \\
\hline 4 & 62 & Male & Infection & $\mathrm{DH}$ & TEA & Septic loosening \\
\hline 5 & 52 & Female & Infection & DH & TEA & Septic loosening \\
\hline 6 & 30 & Female & Sarcoma, NOS & $\mathrm{PH}$ & Proximal humeral EPR & Aseptic loosening \\
\hline 7 & 49 & Male & Malignant bone tumor, NOS & $\mathrm{PH}$ & None & Tumor \\
\hline 8 & 65 & Female & Infection & DH & $\begin{array}{l}\text { ORIF; } \\
\text { TEA }\end{array}$ & Septic loosening \\
\hline 9 & 23 & Male & Ewing's sarcoma & Humeral diaphysis & None & Tumor \\
\hline
\end{tabular}

CPS = Compress ${ }^{\mathbb{R}}$ Compliant Pre-stress Device; NOS = not otherwise specified; DH = distal humerus; $\mathrm{PH}=$ proximal humerus; ORIF $=$ open reduction and internal fixation; $\mathrm{APC}=$ allograft-prosthetic composite; TEA = total elbow arthroplasty; $\mathrm{EPR}=$ endoprosthetic reconstruction.

Table 3. Revision of compressive osseointegration endoprostheses in the upper extremity

\begin{tabular}{|c|c|c|c|c|c|c|c|}
\hline Patient & CPS implant & $\begin{array}{l}\text { Anchor plug size/ } \\
\text { number fixation pins }\end{array}$ & $\begin{array}{l}\text { Amount } \\
\text { of force } \\
\text { (pounds) }\end{array}$ & $\begin{array}{l}\text { Revision for } \\
\text { CPS failure }\end{array}$ & $\begin{array}{l}\text { CPS implant } \\
\text { survival } \\
\text { (months) }\end{array}$ & Any-cause revision & $\begin{array}{l}\text { Followup } \\
\text { (months) }\end{array}$ \\
\hline 1 & $\mathrm{DH}$ & $12 \mathrm{~mm} / 5 \mathrm{pins}$ & 400 & No & 72 & None & 68 \\
\hline 2 & $\begin{array}{l}\text { DH } \\
\text { PU } \\
\text { PU }\end{array}$ & $\begin{array}{l}11 \mathrm{~mm} / 5 \text { pins } \\
2.9 \mathrm{~mm} / 5 \text { pins } \\
3.9 \mathrm{~mm} / 5 \text { pins }\end{array}$ & $\begin{array}{l}400 \\
400 \\
400\end{array}$ & $\begin{array}{l}\text { No } \\
\text { Yes } \\
\text { No }\end{array}$ & $\begin{array}{l}64 \\
6 \\
48\end{array}$ & $\begin{array}{l}\text { Revision standard ulnar } \\
\text { component for aseptic } \\
\text { loosening; revision for lack of } \\
\text { fixation CPS ulnar component }\end{array}$ & 66 \\
\hline 3 & DH & $8 \mathrm{~mm} / 6$ pins & 200 & No & 24 & None & 24 \\
\hline 4 & DH & Custom/5 pins & 400 & No & 83 & Revision for bushing exchange & 83 \\
\hline 5 & $\mathrm{DH}$ & Unknown/5 pins & 400 & No & 14 & None & 14 \\
\hline 6 & $\mathrm{PH}$ & $14 \mathrm{~mm} / 5 \mathrm{pins}$ & 400 & No & 54 & $\begin{array}{l}\text { Débridement }+ \text { implant retention } \\
\text { for superficial infection }\end{array}$ & 54 \\
\hline 7 & $\mathrm{PH}$ & $10 \mathrm{~mm} / 5 \mathrm{pins}$ & 600 & No & 101 & $\begin{array}{l}\text { Joint capsule reconstruction for } \\
\text { glenohumeral instability; } \\
\text { two-stage revision }+ \text { soft tissue } \\
\text { flap for deep infection and skin } \\
\text { erosion (CPS retained) }\end{array}$ & 141 \\
\hline 8 & $\begin{array}{l}\mathrm{DH} \\
\mathrm{DH}\end{array}$ & $\begin{array}{l}11 \mathrm{~mm} / 5 \text { pins } \\
11 \mathrm{~mm} / 5 \text { pins }\end{array}$ & $\begin{array}{l}400 \\
400\end{array}$ & $\begin{array}{l}\text { Yes } \\
\text { No }\end{array}$ & $\begin{array}{l}6 \\
66\end{array}$ & $\begin{array}{l}\text { Revision for lack of CPS fixation, } \\
\text { interface collapse; } \\
\text { revision standard ulnar component } \\
\text { for aseptic loosening }\end{array}$ & 72 \\
\hline 9 & $\begin{array}{l}\text { Humeral } \\
\text { diaphysis } \\
\text { (2) }\end{array}$ & $\begin{array}{l}\text { Unknown/5 pins } \\
\text { Unknown/5 pins }\end{array}$ & $\begin{array}{l}400 \\
400\end{array}$ & $\begin{array}{l}\text { No } \\
\text { No }\end{array}$ & $\begin{array}{l}39 \\
39\end{array}$ & $\begin{array}{l}\text { None } \\
\text { None }\end{array}$ & $\begin{array}{l}36 \\
36\end{array}$ \\
\hline
\end{tabular}

CPS = Compress ${ }^{\mathbb{R}}$ Compliant Pre-stress Device; DH = distal humerus; PU = proximal ulna; PH = proximal humerus.

and the additional intercalary segments were assembled to give the appropriate limb length.

Postoperatively, patients were treated with prophylactic antibiotics for 24 hours. Protocols for postoperative ROM and progression to activity slightly varied based on institution. Patients with proximal humeral implants generally wore a shoulder immobilizer, were limited to 5 pounds of lifting, and allowed pendulum exercises for 6 weeks. Progressive active ROM as tolerated was allowed from 6 to 12 weeks and weightlifting beyond 10 pounds was restricted indefinitely. For reconstructions involving the humeral diaphysis and elbow, progressive active ROM of the 
Table 4. Modes of failure and complications after upper extremity compressive endoprosthetic reconstruction

\begin{tabular}{|c|c|c|c|c|c|}
\hline $\begin{array}{l}\text { Patient } \\
\text { number }\end{array}$ & $\begin{array}{l}\text { CPS } \\
\text { bone }\end{array}$ & Mode of CPS failure & $\begin{array}{l}\text { Timing of CPS } \\
\text { failure (months) }\end{array}$ & Other mechanical failures & Other complications \\
\hline 1 & DH & None & N/A & None & Transient radial nerve palsy \\
\hline \multirow[t]{3}{*}{2} & DH & None & N/A & $\begin{array}{l}\text { Type } 2 \text { (aseptic loosening) standard } \\
\text { ulnar component-revised to CPS }\end{array}$ & None \\
\hline & PU & $\begin{array}{l}\text { Type } 3 \text { (structural) fracture of ulnar } \\
\text { traction bar, periprosthetic fracture }\end{array}$ & 6 & None & None \\
\hline & PU & None & N/A & None & None \\
\hline 3 & DH & None & N/A & None & None \\
\hline 4 & DH & None & N/A & Type 3 (structural) bushing exchange & $\begin{array}{l}\text { Ulnar nerve distribution } \\
\text { numbness }\end{array}$ \\
\hline 5 & DH & None & N/A & None & None \\
\hline 6 & PH & None & N/A & None & $\begin{array}{l}\text { Superficial infection, inferior } \\
\text { glenohumeral subluxation }\end{array}$ \\
\hline 7 & $\mathrm{PH}$ & None & N/A & $\begin{array}{l}\text { Type } 4 \text { (deep infection) } \\
\text { Type } 1 \text { (glenohumeral instability) }\end{array}$ & None \\
\hline \multirow[t]{2}{*}{8} & DH & $\begin{array}{l}\text { Type } 3 \text { (structural) deficient bone, } \\
\text { failure of fixation }\end{array}$ & 5 & None & None \\
\hline & DH & None & N/A & None & None \\
\hline \multirow[t]{2}{*}{9} & HD & None & N/A & None & None \\
\hline & HD & None & N/A & None & None \\
\hline
\end{tabular}

CPS = Compress ${ }^{\circledR}$ Compliant Pre-stress Device; DH = distal humerus; $\mathrm{PH}=$ proximal humerus; PU = proximal ulna; HD = humeral diaphysis, $\mathrm{N} / \mathrm{A}=$ not applicable.

shoulder and elbow was allowed once the wounds were healed. Lifting was restricted similar to the proximal humerus indefinitely.

\section{Outcomes Assessment}

Patients were seen in the clinic at 2, 6, and 12 weeks postoperatively and then every 3 months for the first year. Patients who had an arthroplasty then were followed on a yearly basis, and patients with tumors continued to be followed up every 3 months for Year 2, every 6 months from Years 3 to 5 , and then yearly. Radiographs were performed at each visit.

\section{Statistical Analysis}

Given the small sample size, we report descriptive statistics alone. Proportions are presented to quantify revisions and surgical complications.

\section{Results}

Overall, the proportion of patients requiring any-cause revision was four of eight. Of the 12 implants accounted for beyond 2 years, six had undergone revision of any kind
(Table 3). Only two implant revisions in two patients were attributable to lack of CPS fixation at the bone-implant interface; one of these patients had periprosthetic and implant fracture develop through the traction bar. These modes of failure can be defined as Type 3 structural failures (as per the classification system of Henderson et al. [17]). One patient (Patient 8) with a distal humeral CPS (Fig. 1) had lack of spindle fixation and ingrowth owing to deficient osseous support at 5 months postoperatively (Fig. 2). The second patient (Patient 2) with a distal humeral CPS underwent implantation of a custom proximal ulnar CPS owing to aseptic loosening of the standard, cemented ulnar component. This ulnar CPS component subsequently underwent revision for lack of incorporation and subsequent fracture through the traction bar at 6 months (Fig. 3). Both of these patients had initial conversion surgery with implantation of a CPS in the setting of a multiply operated extremity with allograft-prosthetic composite reconstruction, and both underwent revision surgery with implantation of another CPS. Four hundred pounds of force were selected for all but two patients; five transfixation pins were used in all but one patient who received six pins.

Other modes of failure were aseptic loosening, polyethylene wear, and infection [17]. Aseptic loosening of the standard ulnar component occurred in two patients (two implants): Patient 2 (previously described) and 


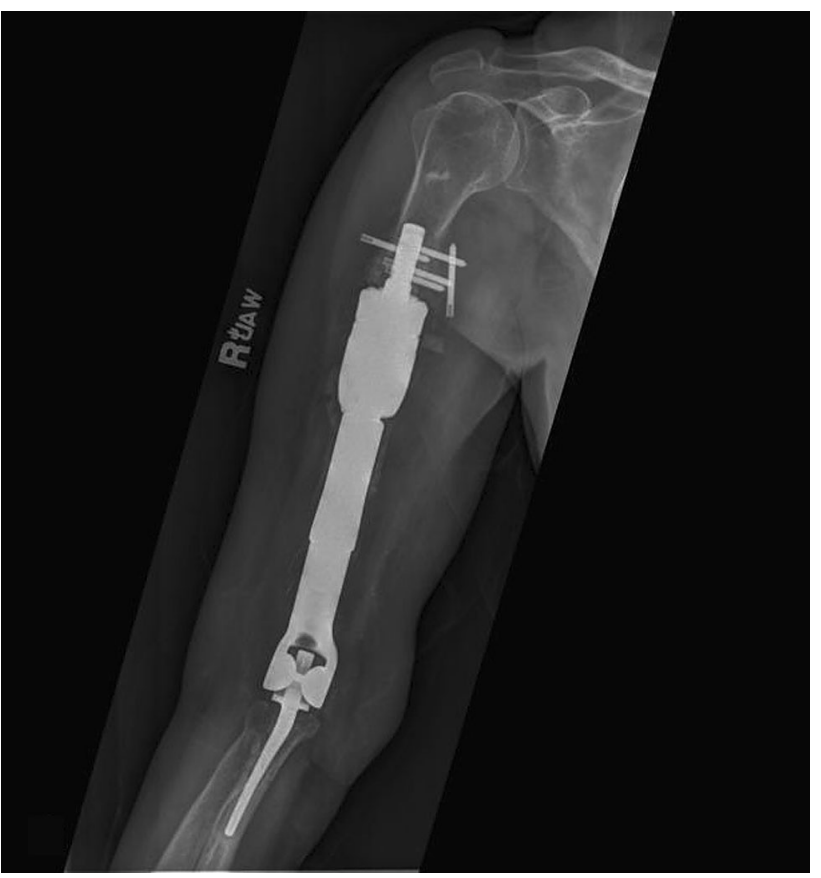

Fig. 1 The plain radiograph shows early structural failure with lack of ingrowth and bone-prosthesis interface collapse at 5 months postoperatively in Patient 8 who had a distal humeral CPS implanted for a failed total elbow arthroplasty. This implant was successfully revised to another CPS device.

Patient 8, who underwent eventual revision surgery with implantation of a stemmed, cemented radial component after aseptic loosening of two standard ulnar components. One patient (one implant) underwent exchange of polyethylene bushings at 83 months. One patient (Patient 7) had recurrent instability, skin erosion, and infection resulting in a two-stage exchange with the addition of a glenoid component and constrained liner. A free soft tissue transfer was performed for implant coverage and wound closure. The CPS spindle was well fixed and was retained during the two-stage exchange where all other metal components were exchanged. No recurrence of infection has occurred at 8 years followup.

Surgical complications included recurrent instability (2), skin breakdown (1), infections (2), and nerve palsy (2) (Table 4). Overall, four of nine patients had a complication develop postoperatively. One patient had a transient radial nerve palsy develop that resolved spontaneously at 9 months, and one patient had an ulnar nerve sensory neurapraxia. One patient with inferior subluxation of the glenohumeral joint had a superficial infection develop that successfully resolved with irrigation, débridement, and implant retention at 3 years postoperatively. There were no local recurrences in patients with bone tumors and no secondary amputations. All patients remain alive without evidence of disease.
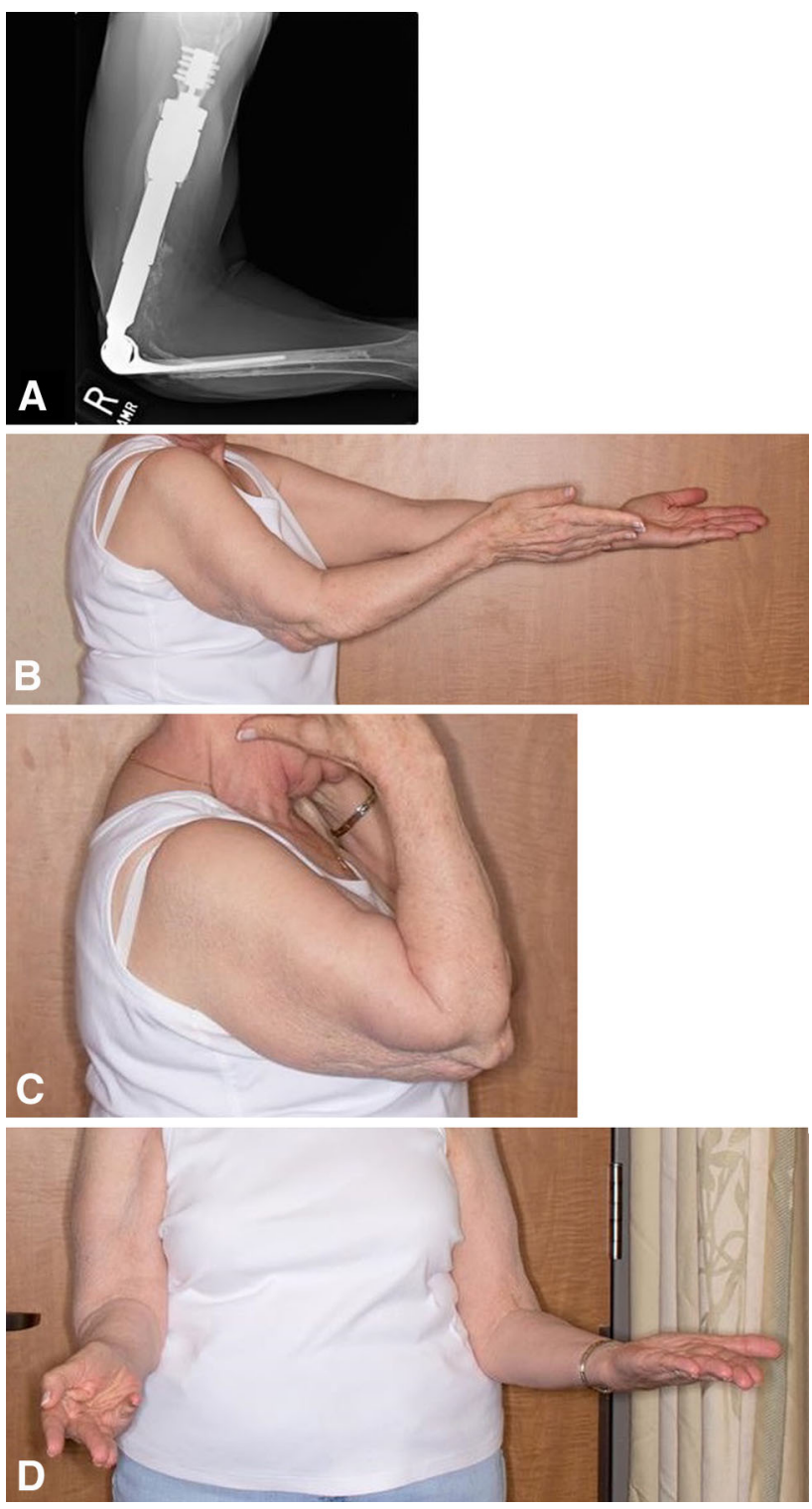

Fig. 2A-D (A) A plain radiograph shows a well-fixed, revised distal humeral CPS and cemented radial component 1.5 years after two subsequent revisions for aseptic loosening of the ulnar component in Patient 8. The patient is showing (B) elbow extension, (C) flexion, and (D) supination.

\section{Discussion}

Despite advances in modern endoprosthetic designs, reconstruction of massive bone loss in the upper extremity remains a challenge. An alternative to stemmed endoprostheses is self-adjusting, compliant, compressive osseointegration. The goal of this approach is to stimulate osseointegration and permanent biologic fixation by creating compression at the bone-implant interface. The implant design aims to avoid stem stress shielding and prevent osteolytic wear debris from accessing the intramedullary canal, thus decreasing the prevalence of aseptic loosening. The use of this implant in 
Fig 3A-B (A) A plain radiograph shows a well-fixed distal humeral compression implant adjacent to a failed ulnar compression component in Patient 2. The mode of failure was lack of ingrowth, periprosthetic fracture at the bone-prosthesis interface, and prosthetic fracture through the titanium traction bar. (B) The patient underwent revision surgery with implantation of another compression endoprosthesis.
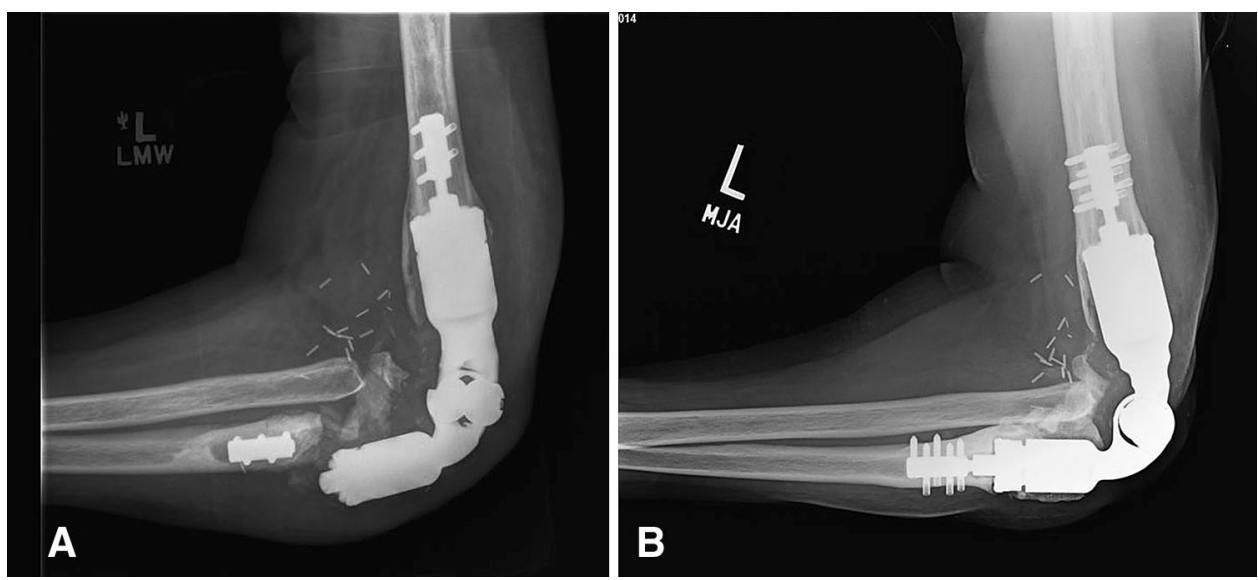

Table 5. Summary of outcomes in upper extremity endoprosthetic reconstruction

\begin{tabular}{|c|c|c|c|c|c|c|c|c|c|}
\hline Study & $\begin{array}{l}\text { Endoprosthesis } \\
\text { type }\end{array}$ & $\begin{array}{l}\text { Sample size total } \\
\text { (upper } \\
\text { extremity) }\end{array}$ & Location & $\begin{array}{l}\text { Aseptic } \\
\text { loosening }\end{array}$ & Infection & $\begin{array}{l}\text { Any- } \\
\text { cause } \\
\text { revision }\end{array}$ & $\begin{array}{l}\text { Periprosthetic } \\
\text { fracture }\end{array}$ & $\begin{array}{l}\text { Secondary } \\
\text { amputation }\end{array}$ & $\begin{array}{l}\text { Mean } \\
\text { followup } \\
\text { (months) }\end{array}$ \\
\hline Current study & CPS & 8 & $\begin{array}{c}2 \mathrm{PH}, 6 \mathrm{DH}, \\
1 \\
\text { diaphysis }\end{array}$ & 2 ulna & 2 & 4 & 0 & 0 & 68 \\
\hline Tyler et al. [29] & CPS & $221(6)$ & $2 \mathrm{PH}, 4 \mathrm{DH}$ & NR & NR & 0 & $\begin{array}{l}0 \text { (all } 6 \text { lower } \\
\text { extremity) }\end{array}$ & 0 & 50 \\
\hline Kulkarni et al. [18] & Stemmed EPR & 10 & $\mathrm{DH}$ & 3 & 0 & 4 & 0 & 0 & 96 \\
\hline Abudu et al. [1] & Stemmed EPR & $18(2)$ & 2 diaphysis & 2 & 0 & 2 & 0 & 0 & $\begin{array}{l}65 \\
(\text { median})\end{array}$ \\
\hline $\begin{array}{l}\text { Ahlmann \& } \\
\quad \text { Menendez [2] }\end{array}$ & Stemmed EPR & $6(1)$ & 1 diaphysis & 1 & 0 & 1 & 0 & 0 & 21.6 \\
\hline Raiss et al. [24] & Stemmed EPR & 39 & $\mathrm{PH}$ & 1 & 2 & 5 & 0 & 1 & 38 \\
\hline Cannon et al. 8] & Stemmed EPR & 83 & $\mathrm{PH}$ & 0 & 2 & 2 & 0 & 0 & 30 \\
\hline Kumar et al. [19] & Stemmed EPR & 100 & $\mathrm{PH}$ & 6 & 1 & 7 & 0 & 8 & 108 \\
\hline $\begin{array}{l}\text { Asavamongkolkul } \\
\text { et al. [3] }\end{array}$ & $\begin{array}{l}\text { Custom } \\
\text { Stemmed } \\
\text { EPR }\end{array}$ & 59 & $\begin{array}{l}30 \mathrm{PH}, \\
4 \mathrm{DH}, 9 \\
\text { diaphysis }\end{array}$ & 2 & 2 & 2 & 0 & 3 & 90 \\
\hline
\end{tabular}

CPS $=$ Compress ${ }^{\mathbb{R}}$ Compliant Pre-stress Device; EPR = endoprosthetic replacement; $\mathrm{PH}=$ proximal humerus; $\mathrm{DH}=$ distal humerus; NR = not reported.

patients with multiply operated extremities with severe bone deficiency is relatively novel in the upper limb. To our knowledge, only two case reports have been published addressing outcomes of four distal humeral compression implants $[10,15]$. The patients in those studies are included in the current study with extended followup, additional surgical indications and implant locations across different institutions to provide a viable, alternative method of reconstruction for difficult salvage reconstructions in the upper limb.

There are several study limitations worth mentioning. The first is selection bias; the majority of our patients underwent very complex reconstructions, and often there were previous cement mantles and very thin remaining cortices. In these scenarios, the CPS implant was selected as an option to obtain a biologic solution where cemented options otherwise had failed, to gain fixation without removing the whole cement mantle (in those without infection) and to preserve more bone. We included all cases of patients from each respective institution, contacted other institutions known to be using the CPS implant, and the biomedical device company to identify other patients in whom this implant had been used as a result of its rarity. However, we have not captured data for every patient who was offered a different type of reconstruction or an amputation during the same time. Second, the small size and heterogeneity of the patient population make it difficult to compare results by diagnosis or anatomic site in the 
upper extremity. Since the study is not powered nor designed to detect differences among these groups, we avoided comparisons and simply report the results of each reconstruction. In addition, our followup was short, and we expect that failures of some of these reconstructions may yet occur. Moreover, one patient was lost to followup before 2 years, and one patient who had 2 years followup (Patient 3) has not been evaluated during the last 6 years, thus we cannot be certain of the status of these reconstructions. Third, the multiinstitutional nature of the patient population may contribute to differences in surgical techniques and postoperative management, which might influence outcomes. However, surgical technique followed the implant manufacturer's recommended technique in all instances, and slight but minor variations in postoperative protocols were observed among centers.

Little is known about the behavior of the CPS in the upper extremity, but some reports have found the CPS to be generally reliable in the lower extremity [4, 12, 23], with 5and 10-year implant survivorship ranging from $80 \%$ to $89 \%$
[16, 21]. Our series of complex upper limb reconstructions had a large proportion of patients who underwent revision surgery, however, revision of the CPS component was less common (two patients; two of 12 implants). These structural prosthetic failures were characterized by failure of spindle ingrowth, bone-implant interface collapse, and fracture of the traction bar in the second patient, similar to other studies of this implant [16, 21, 29]. Both of our failures occurred within the first 6 months of the index surgery, corroborating the findings of Healey et al. [16] that nearly all CPS mechanical failures occur early during the course of treatment. Modes of failure in the upper extremity tend to be sitespecific, with aseptic loosening being common (Table 5). Numerous studies have reported the outcomes after implantation of stemmed endoprostheses in the proximal humerus [3, 8, 11, 14, 20, 22, 24-26, 28, 30, 32], with longterm implant survivorship ranging from $87 \%$ to $97 \%$ [8, 19]. Surgical outcomes have improved with modern endoprosthetics [3, 8, 11], and rates of aseptic loosening are less common than in the lower extremity, ranging from $0 \%$ to
Fig. 4A-F (A) A preoperative radiograph for Patient 9, a 22 year-old man with Ewing's sarcoma of the proximal humerus, shows a poorly delineated lesion involving the humeral diaphysis with features of a primary, malignant bone sarcoma with soft tissue extension. Reconstruction using an intercalary compression implant was performed, and the patient's postoperative (B) AP and (C) lateral radiographs are shown. The patient is shown demonstrating ROM of his shoulder (D) in external rotation, (E) forward flexion, and $(\mathbf{F})$ internal rotation.
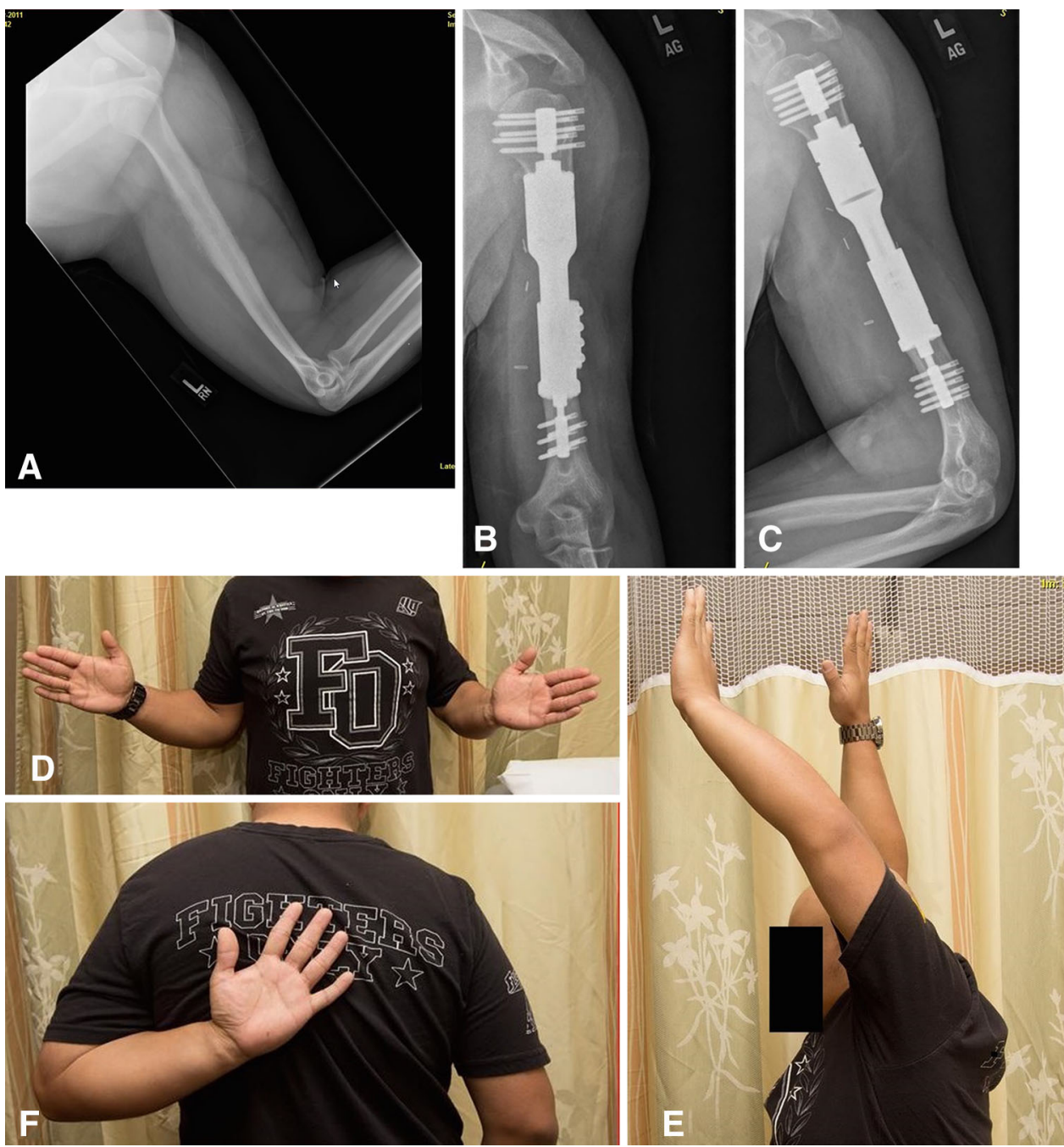
$7 \%$ in series mostly consisting of primary resection and reconstruction [3, 8, 9, 13, 19, 24]. Aseptic loosening did not occur in either of our patients with proximal humeral endoprostheses, but did prompt revision of the standard, cemented ulnar component in two of our patients with the distal humeral CPS. Similarly, Kulkarni et al. [18] reported on three of 10 patients with distal humeral stemmed endoprostheses who underwent revision for aseptic loosening of the humeral component, and an additional three had an exchange of polyethylene bushings at a later stage. Diaphyseal resections are rare, but aseptic loosening is exceedingly common and approaches $100 \%$ in small, heterogeneous retrospective series $[1,2]$. This is in contrast to our patient (Fig. 4A), who despite a short followup of 36 months, has retained both CPS implants (Fig. 4B-C) and has good function (Fig. 4D-F).

The patients in this series underwent large, difficult reconstructions, and so it is not surprising that surgical complications were relatively common (Table 4). Many of these complications were site-specific, in particular those involving nerve injuries. We observed radial nerve palsy and an ulnar sensory neurapraxia, which both resolved spontaneously in one patient each and were associated with distal humeral resections. Kulkarni et al. [18] reported that no patient had nerve palsy, deep infection, or local recurrence, or needed a secondary amputation with distal humeral replacement in their series. Glenohumeral instability is commonplace after proximal humerus reconstruction, although many patients can be managed nonoperatively [3, 8, 19]. Raiss et al. [24] reported four humeral head dislocations in 39 stemmed MUTARS $^{\circledR}$ implants (implantcast, Buxtehude, Germany); two underwent revision surgery to correct the version. Proximal humeral migration occurred in $29 \%$ of patients along with five anterior dislocations in the series reported by Cannon et al. [8]; however, only one needed revision. In our series, both patients with proximal humerus reconstructions had subluxation develop; one underwent two-stage revision with implantation of a constrained liner and free flap coverage for skin erosion and infection; the other patient was managed nonoperatively.

\section{Conclusion}

The use of endoprostheses using principles of compressive osseointegration is not widespread in the upper extremity. We observed timing and modes of CPS failure that are in keeping with those reported for the lower extremity. Our study showed that this technology adds to the armamentarium of surgical options for the experienced upper limb surgeon when dealing with massive bone loss, extremely poor bone quality, and difficult revision surgery. Of particular benefit is the ability to preserve juxtaarticular bone in long resections with short remaining end segments and in young patients who may need future revision surgery during their lifetime. Surgeons must inform patients, however, that these are salvage operations, and revision surgery is common. Long-term followup of more patients is necessary to further document the survivorship of these implants in the upper extremity.

Acknowledgments We thank Nathalie Ste-Marie MSc (Department of Surgery, McGill University) for assistance with manuscript preparation, and Julie M. Daniels CCRP (Department of Orthopaedic Surgery and Rehabilitation, Vanderbilt University) for assistance with data collection for this study.

\section{References}

1. Abudu A, Carter SR, Grimer RJ. The outcome and functional results of diaphyseal endoprostheses after tumour excision. $J$ Bone Joint Surg Br. 1996;78:652-657.

2. Ahlmann ER, Menendez LR. Intercalary endoprosthetic reconstruction for diaphyseal bone tumours. J Bone Joint Surg Br. 2006;88:1487-1491.

3. Asavamongkolkul A, Eckardt JJ, Eilber FR, Dorey FJ, Ward WG, Kelly CM, Wirganowicz PZ, Kabo JM. Endoprosthetic reconstruction for malignant upper extremity tumors. Clin Orthop Relat Res. 1999;360:207-220.

4. Bhangu AA, Kramer MJ, Grimer RJ, O’Donnell RJ. Early distal femoral endoprosthetic survival: cemented stems versus the Compress implant. Int Orthop. 2006;30:465-472.

5. Biomet Orthopedics. Compress Compliant Pre-stress Device Orthopaedic Salvage System: Surgical Technique. Available at: http://www.biomet.com/wps/wcm/connect/internet/2ae431be-8bf541bd-bc2c-bd164e216815/BMET0247.1.pdf?MOD=AJPERES\& CONVERT TO=url\&CACHEID $=2 \mathrm{ae} 431 \mathrm{be}-8 \mathrm{bf5}-41 \mathrm{bd}-\mathrm{bc} 2 \mathrm{c}-\mathrm{bd} 16$ 4e216815. Accessed January 13, 2017

6. Calvert GT, Cummings JE, Bowles AJ, Jones KB, Wurtz LD, Randall RL. A dual-center review of compressive osseointegration for fixation of massive endoprosthetics: 2- to 9-year followup. Clin Orthop Relat Res. 2014;472:822-829.

7. Calvert GT, Wright J, Agarwal J, Jones KB, Randall RL. Is claviculo pro humeri of value for limb salvage of pediatric proximal humerus sarcomas? Clin Orthop Relat Res. 2015;473:877-882.

8. Cannon CP, Paraliticci GU, Lin PP, Lewis VO, Yasko AW. Functional outcome following endoprosthetic reconstruction of the proximal humerus. J Shoulder Elbow Surg. 2009;18:705-710.

9. Creighton JJ Jr, Peimer CA, Mindell ER, Boone DC, Karakousis $\mathrm{CP}$, Douglass HO. Primary malignant tumors of the upper extremity: retrospective analysis of one hundred twenty-six cases. J Hand Surg Am. 1985;10(6 pt 1):805-814.

10. Davis JM, Robins RJ, Frink SJ, Rispoli DM. Use of a compression tumor implant with total elbow arthroplasty for traumatic distal humeral bone loss in a young woman. J Shoulder Elbow Surg. 2010;19:e24-28.

11. El-Sherbiny M. Reconstruction of the proximal humerus after wide resection of tumors: comparison of three reconstructive options. J Egypt Natl Canc Inst. 2008;20:369-378.

12. Farfalli GL, Boland PJ, Morris CD, Athanasian EA, Healey JH. Early equivalence of uncemented press-fit and Compress femoral fixation. Clin Orthop Relat Res. 2009;467:2792-2799.

13. Fink B, Strauss JM, Lamla U, Kurz T, Guderian H, Ruther W. [Endoprosthetic surface replacement of the head of the humerus][in German]. Orthopade. 2001;30:379-385. 
14. Frassica FJ, Frassica DA. Evaluation and treatment of metastases to the humerus. Clin Orthop Relat Res. 2003;(415 suppl):S212-218.

15. Hattrup SJ, Beauchamp CP. Custom reconstruction of the distal part of the humerus using compressive osseointegration. JBJS Case Connect. 2012;2: e54.

16. Healey JH, Morris CD, Athanasian EA, Boland PJ. Compress knee arthroplasty has $80 \%$ 10-year survivorship and novel forms of bone failure. Clin Orthop Relat Res. 2013;471:774-783.

17. Henderson ER, Groundland JS, Pala E, Dennis JA, Wooten R, Cheong D, Windhager R, Kotz RI, Mercury M, Funovics PT, Hornicek FJ, Temple HT, Ruggieri P, Letson GD. Failure mode classification for tumor endoprostheses: retrospective review of five institutions and a literature review. J Bone Joint Surg Am. 2011;93:418-429.

18. Kulkarni A, Fiorenza F, Grimer RJ, Carter SR, Tillman RM. The results of endoprosthetic replacement for tumours of the distal humerus. J Bone Joint Surg Br. 2003;85:240-243.

19. Kumar D, Grimer RJ, Abudu A, Carter SR, Tillman RM. Endoprosthetic replacement of the proximal humerus: long-term results. J Bone Joint Surg Br. 2003;85:717-722.

20. Meller I, Bickels J, Kollender Y, Ovadia D, Oren R, Mozes M. Malignant bone and soft tissue tumors of the shoulder girdle: a retrospective analysis of 30 operated cases. Acta Orthop Scand. 1997;68:374-380.

21. Monument MJ, Bernthal NM, Bowles AJ, Jones KB, Randall RL. What are the 5-year survivorship outcomes of compressive endoprosthetic osseointegration fixation of the femur? Clin Orthop Relat Res. 2015;473:883-890.

22. Olsson E, Andersson D, Brostrom LA, Wallensten R, Nilsonne U. Shoulder function after prosthetic replacement of proximal humerus. Ann Chir Gynaecol. 1990;79:157-160.

23. Pedtke AC, Wustrack RL, Fang AS, Grimer RJ, O'Donnell RJ. Aseptic failure: how does the Compress ${ }^{\mathbb{B}}$ implant compare to cemented stems? Clin Orthop Relat Res. 2012;470:735-742.
24. Raiss P, Kinkel S, Sauter U, Bruckner T, Lehner B. Replacement of the proximal humerus with MUTARS tumor endoprostheses. Eur J Surg Oncol. 2010;36:371-377.

25. Safran MR, Kody MH, Namba RS, Larson KR, Kabo JM, Dorey FJ, Eilber FR, Eckardt JJ. 151 endoprosthetic reconstructions for patients with primary tumors involving bone. Contemp Orthop. 1994;29:15-25.

26. Salzer M, Knahr K, Locke H, Stärk N, Matejovsky Z, Plenk H Jr, Punzet G, Zweymüller K. A bioceramic endoprosthesis for the replacement of the proximal humerus. Arch Orthop Trauma Surg. 1979;93:169-184.

27. Tang X, Guo W, Yang R, Tang S, Yang Y. Custom-made prosthesis replacement for reconstruction of elbow after tumor resection. J Shoulder Elbow Surg. 2009;18:796-803.

28. Teunis T, Nota SP, Hornicek FJ, Schwab JH, Lozano-Calderon SA. Outcome after reconstruction of the proximal humerus for tumor resection: a systematic review. Clin Orthop Relat Res. 2014;472:2245-2253.

29. Tyler WK, Healey JH, Morris CD, Boland PJ, O'Donnell RJ. Compress $\AA$ periprosthetic fractures: interface stability and ease of revision. Clin Orthop Relat Res. 2009;467:2800-2806.

30. van de Sande MA, Dijkstra PD, Taminiau AH. Proximal humerus reconstruction after tumour resection: biological versus endoprosthetic reconstruction. Int Orthop. 2011;35:1375-1380.

31. Wang ML, Ballard BL, Kulidjian AA, Abrams RA. Upper extremity reconstruction with a humeral tumor endoprosthesis: a novel salvage procedure after multiple revisions of total shoulder and elbow replacements. J Shoulder Elbow Surg. 2011;20:e1-8.

32. Wright EH, Gwilym S, Gibbons CL, Critchley P, Giele HP. Functional and oncological outcomes after limb-salvage surgery for primary sarcomas of the upper limb. J Plast Reconstr Aesthet Surg. 2008;61:382-387. 